\title{
Prospective study of the efficacy of antibiotics versus antitussive drugs for the management of URTI-related acute cough in children
}

Alessandro Zanasi $i^{*}$, Luigi Lanata ${ }^{2}$, Federico Saibene ${ }^{2}$, Giovanni Fontana ${ }^{3}$, Peter V. Dicpinigaitis ${ }^{4}$, Valentina Venier $^{2}$ and Francesco De Blasio ${ }^{5}$

\begin{abstract}
Background: Acute cough is one of the most frequent symptoms prompting a visit to a health care provider, usually following a viral upper respiratory tract infection (URTI). The disproportionate use of antibiotics in children with URTIs, recently highlighted in the medical literature, could lead to associated side effects, without any beneficial effect. Although an early, albeit inappropriate, antibiotic prescription increases parental satisfaction, URTIs are predominantly viral infections and are generally self-limiting. Therefore the aim of this study was to analyze the effectiveness of antibiotics compared to symptomatic drugs (central and peripheral antitussives) on URTI-related cough in a pediatric population.

Methods: This is a prospective observational study of 330 children who required pediatric consultation for acute cough. Severity, frequency and type of cough were assessed at baseline and after 6 days of treatment (antitussives $n=123$, antibiotics $n=89$ or combination of them $n=38)$ or no treatment $(n=80)$. The outcome of cough management after 6 days was analyzed in terms of resolution, improvement, no change or worsening of symptoms. Study assessments were performed using a standardized questionnaire administered to parents.

Results: Between children treated with antitussives or antibiotics, there was a statistically significant difference in the resolution of cough. Moreover, if considering peripheral antitussives, the resolution of cough was significantly higher with antitussives than with antibiotics $(p<0.01)$. There was no difference in cough resolution between children treated with antitussives and those receiving a combination of antibiotics and antitussives, either central and peripheral antitussives.

Conclusion: Antibiotics are generally not useful nor appropriate in treating acute cough due to the common cold. Furthermore, inappropriate antibiotic use introduces the possibility of adverse side effects as well as promotion of antibiotic resistance. The findings of the present study suggest that antitussives, especially peripherally acting agents, represent an effective treatment option for acute pediatric cough caused by URTIs.
\end{abstract}

Keywords: Levodropropizine, Cough, Antibiotic, Antitussives, URTI, Children

\footnotetext{
* Correspondence: alessandro.zanasi@aosp.bo.it

${ }^{1}$ Pneumology Unit, University of Bologna, S.Orsola Malpighi Hospital,

Bologna, Italy

Full list of author information is available at the end of the article
} 


\section{Background}

Antibiotic resistance of pathogenic bacteria is being recognized as a major emerging threat in healthcare settings throughout the world. In addition, the discovery of new molecules with antimicrobial activity is no longer keeping pace with the spread of resistant bacterial pathogens. Therefore local and international efforts and strategies are needed to neutralize this emerging threat [1]. The main contributor to the development, increase and spread of antibiotic resistance is the overuse of antibiotics, particularly in children. Of particular concern is the over-prescription of these drugs to children for the treatment of upper respiratory infections (URTIs) and influenza-like illness.

URTI, the most commonly treated acute problem in primary care, is a pathological condition most often caused by viruses $[2,3]$ and thus, does not require antibiotics [4-6]. However, URTIs are the conditions for which the misuse of antibiotics is particularly high and reported worldwide $[7,8]$ despite the strong evidence on their self-limiting nature. Even some of the bacterial illnesses (such as otitis media and sinusitis) are usually self-limited and antibiotic treatment is not recommended for these conditions [9].

An important factor leading to the inappropriate use of antibiotics in children with URTIs is the difficulty in making a reliable and rapid clinical diagnosis. In fact, distinguishing between the clinical features of influenza and bacterial infections is the main challenge for physicians. Furthermore, doctors may prescribe antibiotics as a response to parents' expectations. A survey of more than 600 pediatricians showed that $96 \%$ had been asked by parents for antibiotics in circumstances for which they were unnecessary [10].

URTI or common cold are by far the most common cause of acute cough, defined as cough of recent onset and lasting for a maximum of 3 weeks. For the treatment of acute cough, symptomatic over-thecounter (OTC) drugs, such as antitussive or mucoactive drugs, are frequently recommended as a first-line intervention [11].

Mainly, two classes of antitussive agents are available for the treatment of cough in children: centrally acting cough suppressants (codeine, dextromethorphan and cloperastine), and peripherally acting antitussives such as levodropropizine, a non-opioid inhibitor of the cough reflex at the peripheral nerve level (sensory $C$ fibres) and a modulator of sensory neuropeptides within the respiratory tract [12]. Hence, in order to analyze the effectiveness of antibiotics compared to symptomatic drugs in improving or eliminating cough caused by URTI, we carried out an analysis of data collected from a prospective study comparing children, with URTI and cough, treated with antitussive drug as symptomatic therapy or antibiotics or their combination.

\section{Methods}

This study is an analysis of data collected during a prospective observational study performed in 2012 [13]. It was performed in children who required a pediatric consultation for acute cough of recent onset ( $\leq 3$ weeks) caused by URTI, from 1st February to 30th April 2010.

Study assessments were performed through a standardized Pediatric Cough Questionnaire (PCQ) developed and approved by the Scientific Committee of the Italian Society of Cough Study. The PCQ consists of two different parts.

Baseline assessment regarding type (dry, productive, mix), frequency, duration and severity of cough (defined as: mild if it did not interfere with common daily activities, moderate if occasionally disturbed common daily activities and severe if interfered with daily activities and night rest) was performed during the first study visit by the pediatrician, who interviewed parents and/or patients, compiled the first part of the PCQ and prescribed the most appropriate treatment for cough.

The PCQ was given to the children's parents to complete the second part 6 days after the first study visit, to document administered treatments and to selfassess outcome of therapy in terms of resolution (cough disappearance), improvement (just few sporadic cough spells), no change in symptoms or worsening of cough (more frequent and severe cough).

Patients presented 1 week after the first visit at which time questionnaires were collected by the physician. Any adverse events were also reported.

According to the aim of this study, questionnaires of patients reported specific types of treatment; in particular, antibiotics or antitussives, combination of antibiotics and antitussives, and no pharmacological treatment, have been selected for analysis.

\section{Statistics}

Continuous variables are presented as mean +/- standard deviation. Categorical and discrete variables are presented as frequency and percentage. Differences between groups were tested using $\chi^{2}$ test for categorical and discrete variables (with Yates correction for $2 \times 2$ tables). Analysis of variance (ANOVA) has been used to analyze the differences between groups for the following two parameters: age (expressed as years) and duration of cough (expressed as days).

The correlation between the treatment and the type of cough (productive, mix or dry), the episodes of cough (occasional, frequent or continuous) and the severity of cough (mild, moderate, severe) was performed by the polychotomous stepwise logistic regression. 


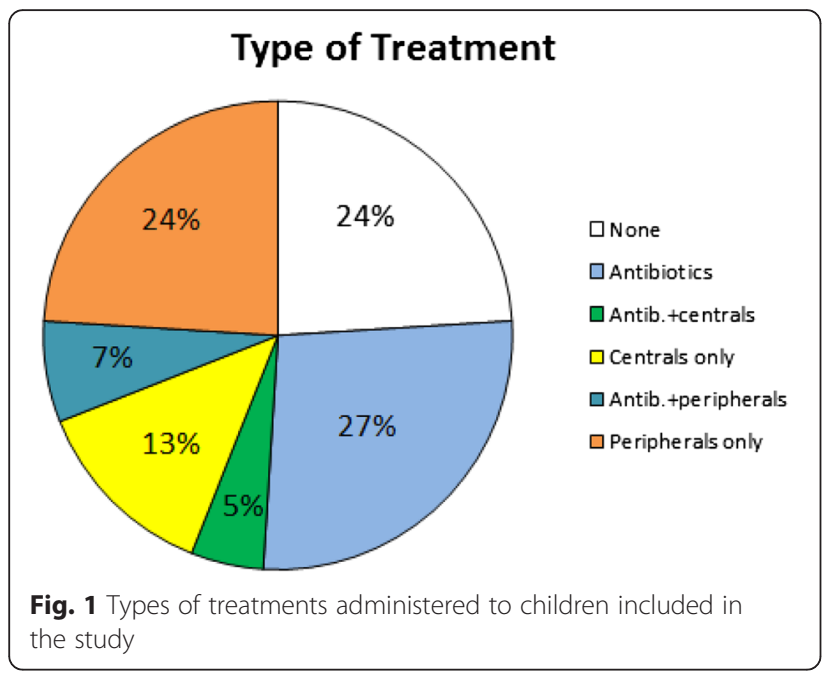

\section{Results}

\section{Epidemiology of cough and clinical findings}

In total, 330 children affected by URTI were evaluated in this analysis. Clinical data including frequency, severity and type of cough were recorded on the PCQ during the first study visit. Tables 1 and 2 reported patients' characteristics at baseline according to different types of treatments.

\section{Treatment of cough}

Eighty-nine children $(27 \%)$ received antibiotics, while $38(12 \%)$ children received a combination of antibiotics and antitussives; central antitussives (codeine or cloperastine) were given in 16 cases (5\%), and peripheral antitussives (levodropropizine) were given to 22 children (7\%). Forty-four and 79 children received central or peripheral antitussives respectively (13 and $24 \%$ ), without antibiotics. Eighty children (24 \%) did not receive any treatment for cough (Fig. 1).

\section{Correlation between treatments outcomes and type of treatment received}

Fifty-one per cent of patients treated with antitussives had an improvement in cough, $41 \%$ reported resolution of cough, and $7 \%$ did not have any change (Fig. 2).

Among the patients receiving peripheral antitussives (levodropropizine), $49 \%$ reported improvement in cough, and $47 \%$ reported the resolution of cough. Four per cent did not have any change in cough symptoms. In the group of children receiving central antitussives, $54.5 \%$ reported improvement in cough, $29.5 \%$ reported resolution of cough, $14 \%$ did not have any change in symptoms and $6 \%$ reported worsened symptoms (Fig. 3).

Table 1 Patients characteritics at baseline according to types of treatments

\begin{tabular}{|c|c|c|c|c|c|}
\hline & $\begin{array}{l}\text { Antibiotic (ANT) } \\
n=89\end{array}$ & $\begin{array}{l}\text { Antitussives (ATT) } \\
n=123\end{array}$ & $\begin{array}{l}\text { Combination (COM) } \\
n=38\end{array}$ & $\begin{array}{l}\text { No Treatment (NT) } \\
n=55\end{array}$ & $p$ \\
\hline Age (years), mean (min-max) & $4.9(0.4-13.0)$ & $6.4(0.8-14.0)$ & $6.5(1.7-13.3)$ & $7.0(0.3-14.0)$ & $p<0.01$ \\
\hline Cough Duration (days), mean (min-max) & $5.7(1.0-21.0)$ & $4.6(2.0-20.0)$ & $6.5(2.0-30.0)$ & $5.0(2.0-1.0)$ & $p<0.05$ \\
\hline \multicolumn{6}{|l|}{ Cough Type (\%) } \\
\hline Productive & $61.8 \%$ & $26 \%$ & $52.6 \%$ & $47.3 \%$ & \multirow[t]{2}{*}{$p<0.01$} \\
\hline Dry & $23.6 \%$ & $64.2 \%$ & $26.3 \%$ & $34.5 \%$ & \\
\hline Mix & $14.6 \%$ & $9.8 \%$ & $21.1 \%$ & $18.2 \%$ & $\begin{array}{l}\text { NS ANT vs ATT, } \\
\text { NS ATT vs COM }\end{array}$ \\
\hline \multicolumn{6}{|l|}{ Cough Intensity (\%) } \\
\hline Mild & $19.1 \%$ & $10.6 \%$ & $0 \%$ & $43.6 \%$ & NS ANT vs ATT \\
\hline Moderate & $36 \%$ & $63.4 \%$ & $34.2 \%$ & $54.5 \%$ & $\begin{array}{l}\text { NS ANT vs ATT, } \\
\text { NS ATT vs COM }\end{array}$ \\
\hline Severe & $44.9 \%$ & $26 \%$ & $65.8 \%$ & $1.8 \%$ & NS ANT vs ATT \\
\hline \multicolumn{6}{|l|}{ Cough Frequency (\%) } \\
\hline Occasional & $22.5 \%$ & $20.3 \%$ & $0 \%$ & $58.2 \%$ & NS ANT vs ATT \\
\hline Frequent & $58.4 \%$ & $71.5 \%$ & $60.5 \%$ & $41.8 \%$ & $\begin{array}{l}\text { NS ANT vs ATT, } \\
\text { NS ATT vs COM }\end{array}$ \\
\hline Continuous & $19.1 \%$ & $8.1 \%$ & $39.5 \%$ & $0 \%$ & NS ANT vs ATT \\
\hline \multicolumn{6}{|l|}{ Concomitant respiratory diseases } \\
\hline Yes & $74.2 \%$ & $72.4 \%$ & $81.6 \%$ & $92.7 \%$ & \multirow[t]{2}{*}{$p<0.05$} \\
\hline No & $25.8 \%$ & $27.6 \%$ & $18.4 \%$ & $7.3 \%$ & \\
\hline \multicolumn{6}{|l|}{ First episode of cough } \\
\hline Yes & $57.3 \%$ & $51.2 \%$ & $63.2 \%$ & $40 \%$ & NS \\
\hline No & $42.7 \%$ & $48.8 \%$ & $36.8 \%$ & $60 \%$ & NS \\
\hline
\end{tabular}


Table 2 Cough characteristics at baseline according to types of administered antitussives (centrals vs levodropropizine)

\begin{tabular}{llll}
\hline & $\begin{array}{l}\text { Central Antitussives } \\
(\mathrm{CA}) n=44\end{array}$ & $\begin{array}{l}\text { Levodropropizine } \\
(\mathrm{LDP}) n=79\end{array}$ & $p$ \\
\hline Cough Type (\%) & & & 0,1773 (NS) \\
Productive & $25 \%$ & $75 \%$ & \\
Dry & $41.8 \%$ & $58.2 \%$ & \\
Mix & $25 \%$ & $75 \% \%$ & 0.7517 (NS) \\
Cough Intensity (\%) & & \\
Mild & $38.5 \%$ & $61.5 \%$ & 0.3869 (NS) \\
Moderate & $33.3 \%$ & $66.7 \%$ & \\
Severe & $40.6 \%$ & $59.4 \%$ & \\
Cough Frequency $\%)$ & & \\
Occasional & $24 \%$ & $76 \%$ & \\
Frequent & $38.6 \%$ & $61.4 \%$ & \\
Continuous & $40 \%$ & $60 \%$ & \\
\hline
\end{tabular}

Fifty-three per cent of patients treated with both antibiotics and antitussives reported improvement in their symptoms. The resolution of cough was reported in $37 \%$ of children. Eight per cent of patients did not have any change and $3 \%$ reported worsening of their condition (Fig. 2).

Considering the patients treated with antibiotics plus levodropropizine, $54.5 \%$ noted improvement in their symptoms and $45 \%$ reported resolution of cough. In the group of patients receiving both antibiotics and central antitussives, $50 \%$ reported an improvement of symptoms, $25 \%$ reported cough resolution, $19 \%$ did not have any change in cough symptoms and $6 \%$ worsened (Fig. 3).
Considering patients treated with antibiotics, $63 \%$ reported an improvement, $24 \%$ reported resolution of cough and $13.5 \%$ did not have any change (Fig. 2).

There was no statistically significant difference in the resolution of cough between patients treated with antitussives and those treated with the combination of antitussives and antibiotics $\left(\chi^{2}=0.053 ; p=N S\right)$.

Comparing children treated with antitussives or antibiotics, there was a statistically significant difference in the resolution of cough $\left(\chi^{2}=5.99 ; p<0.05\right)$ in favor of antitussive drugs.

Including in the analysis the distinction between central and peripheral antitussives, the difference in the resolution of cough between children treated with a peripheral agent (levodropropizine) or antibiotics alone was statistically significant $\left(\chi^{2}=8.998 ; p<0.01\right)$ in favor of levodropropizine. This result did not change when considering only children with severe cough at baseline $\left(x^{2}=8.928 ; p<0.01\right)$. On the contrary, the resolution of cough was not statistically different between children treated with central antitussives or antibiotics $\left(\chi^{2}=0.280 ; p=\mathrm{NS}\right)$.

All statistical analysis results are reported in Tables 3 and 4 .

\section{Discussion}

An interventional strategy is necessary to reduce antibiotic misuse and overuse in pediatric primary care for the treatment of acute cough, including the promotion of other beneficial approaches, such as medications for the amelioration of troublesome symptoms associated with URTI. The use of antibiotics in pediatric URTI remains controversial, despite evidence that the vast

\section{Treatment Outcome Total $\mathrm{n}=\mathbf{3 3 0}$}

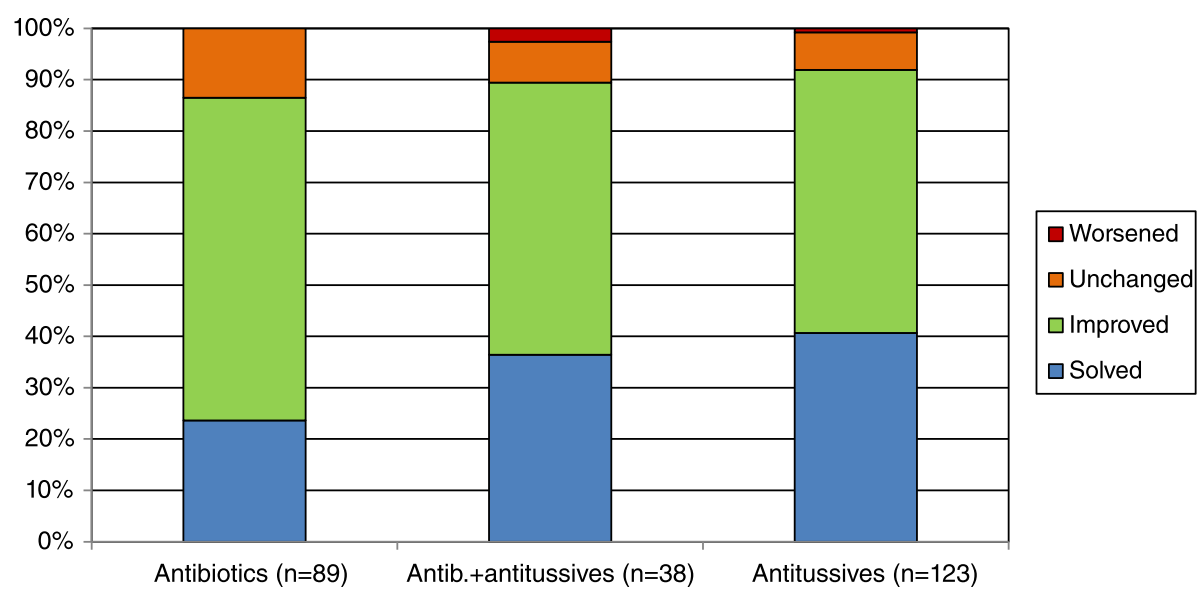

Fig. 2 Treatments outcomes according to different types of administered treatment 


\section{Treatment Outcome Total $\mathrm{n}=\mathbf{3 3 0}$}

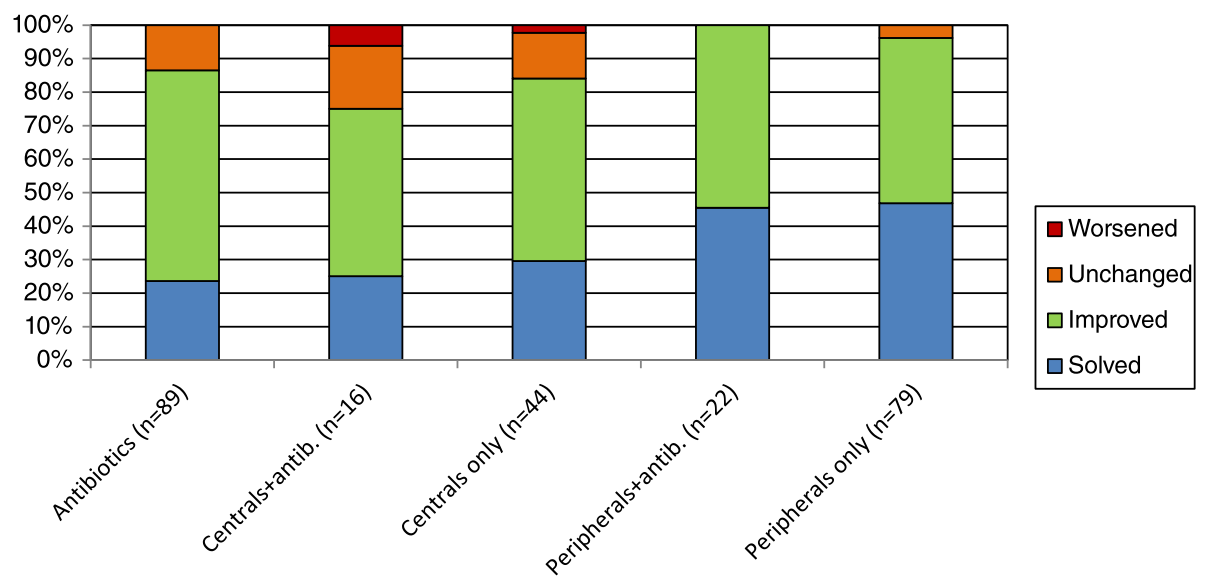

Fig. 3 Treatments outcomes according to different types of treatment including the distinction between central and peripheral antitussive molecules

majority of URTIs has a viral origin. In addition, even if URTIs are caused by bacteria, the probability of their resolution without the administration of antibiotics is high [14]. Since cough is usually the major cause of discomfort in patients presenting with URTI, a symptomatic treatment with antitussive drugs appears to be a reasonable approach to the management of this condition [9].

Nonetheless, from the analysis of questionnaires we found that in the group of children receiving a pharmacological treatment $(76 \%)$ for their URTI symptoms, half were prescribed antibiotics with or without antitussive drugs while the remaining $38.5 \%$ were treated with peripheral or central antitussives.

One important and clinically relevant finding of our study is that there was no statistically significant difference in the percentage of cough resolution between children treated with antitussive compared to children receiving a combination of antibiotics and antitussives. Furthermore, cough resolution in children treated with antitussives was significantly higher than in children

Table 3 Outcome differences between group of treatment: $x^{2}$ test results

\begin{tabular}{ll}
\hline Treatments & Resolution of cough \\
\hline Antibiotics vs antitussives & $x^{2}=5.999(p<0.05)$ \\
Antibiotics vs peripheral antitussives & $x^{2}=8.998(p<0.01)$ \\
Antibiotics vs central antitussives & $x^{2}=0.280(p=N S)$ \\
Antibiotics + antitussives vs antitussives & $x^{2}=0.053(p=N S)$ \\
$\begin{array}{l}\text { Antibiotics + peripheral antituss. } \\
\text { vs peripheral antitussives }\end{array}$ & $x^{2}=0.016(p=N S)$ \\
Antibiotics + central antitussives & $x^{2}=0.001$ ( $\left.p=N S\right)$ \\
vs central antitussives & \\
\hline
\end{tabular}

treated with antibiotics. We also observed that after a week of treatment, levodropropizine significantly solved cough greater than antibiotics did.

Furthermore, this result did not change when considering only children with severe cough at baseline.

Taken together, these findings confirm that the use of antibiotics is of little benefit and it may be not necessary in the symptomatic management of cough associated with URTI, consistent with a previous report [15] in which the management of acute moist cough in the presence of URTI by means of antimicrobial therapy was not superior to the treatment with inhaled mucoactive drugs in the pediatric setting.

The main limitation of our study is its observational design, thus lacking treatment randomization, blinding of both patients and outcome assessors, and homogeneity in groups for treatment at baseline. However, we wanted to evaluate in a real-life pediatric setting the management of acute cough associated with URTI, comparing also the efficacy of the two main

Table 4 Outcome differences between group of treatment in children with severe cough: $x^{2}$ test results

\begin{tabular}{ll}
\hline Treatments & Resolution of cough \\
\hline Antibiotics vs antitussives & $x^{2}=3.738(p=0.0532$, NS) \\
Antibiotics vs peripheral antitussives & $x^{2}=8.928(p<0.01)$ \\
Antibiotics vs central antitussives & $x^{2}=0.000(p=N S)$ \\
Antibiotics + antitussives vs antitussives & $x^{2}=0.218(p=N S)$ \\
$\begin{array}{l}\text { Antibiotics + peripheral antituss. } \\
\text { vs peripheral antitussives }\end{array}$ & $x^{2}=0.000(p=N S)$ \\
Antibiotics + central antitussives & $x^{2}=0.713(p=N S)$ \\
vs central antitussives &
\end{tabular}

NA not applicable 
therapeutic approaches currently in use: antimicrobial vs antitussive therapy.

Finally, another possible limitation is the lack of a microbiological characterization of the URTI. Nonetheless, in the presence of URTI, guidelines for the management of cough in children do not recommend microbiological testing $[15,16]$ but rather, a strategy of no antibiotic or delayed antibiotic prescription, is recommended $[15,17]$.

\section{Conclusion}

Our observational results suggest that acute cough associated with URTI can be effectively managed with symptomatic therapy alone, i.e., central or peripheral antitussives, yielding the same clinical benefits compared with combination therapy that included antibiotics. the present study, levodropropizine appeared to be the most effective option at relieving cough. In light of previously demonstrated efficacy data $[12,18,19]$ and the considerable safety profile of levodropropizine $[18,20]$, these results further support its use for the management of acute pediatric cough associated with URTI. Further large randomized clinical trial in children should be conducted in order to confirm the effectiveness of antitussive drugs used in this observational study.

\section{Competing interests}

This study was supported by Dompé farmaceutici through an unrestricted grant. Lanata, Saibene and Venier are employees of Dompé farmaceutici, Medical Department. Dompé farmaceutici is a company that manufactures and commercializes levodropropizine.

Dicpinigaitis has served as a consultant to Dompé

De Blasio has been member of an International Advisory Group supported by an unrestricted educational grant of Dompé Farmaceutici SpA at National aqs well International meetings.

Giovanni Fontana received research grants or fees from Menarini, Edmond Pharma, Dompé Farmaceutici SpA, Vertona Pharma, AMD.

\section{Authors' contributions}

AZ carried out the conception of the study and set up the task group of the authors. All authors carried out the literature review. All authors carried out the draft paper. All authors read and approved the final manuscript.

\section{Acknowledgements}

The authors would like to thank B Chinea, D Ferrari (Ibis Informatica srl) for their statistical support.

\section{Author details}

${ }^{1}$ Pneumology Unit, University of Bologna, S.Orsola Malpighi Hospital, Bologna, Italy. ${ }^{2}$ Medical Department Dompè Farmaceutici SpA, Milan, Italy. ${ }^{3}$ University Hospital Careggi, Florence, Italy. ${ }^{4}$ Department of Medicine, Albert Einstein College of Medicine and Montefiore Medical Center, Bronx, NY, USA. ${ }^{5}$ Respiratory Medicine and Pulmonary Rehabilitation Section, Clinic Center, Private Hospital, Naples, Italy.

Received: 6 February 2016 Accepted: 19 April 2016

Published online: 13 June 2016

\section{References}

1. Huang N, Morlock L, Lee CH, Chen LS, Chou YJ. Antibiotic prescribing for children with nasopharyngitis (common colds), upper respiratory infections, and bronchitis who have health-professional parents. Pediatrics. 2005;116(4):826-32.
2. Nyquist AC, Gonzales R, Steiner JF, Sande MA. Antibiotic prescribing for children with colds, upper respiratory tract infections, and bronchitis. JAMA. 1998;279(11):875-7.

3. Tan YS, Hong CY, Chong PN, Tan ES, Lew YJ, Lin RT. Knowledge that upper respiratory tract infection resolves on its own is associated with more appropriate health-seeking behaviour and antibiotic cognition. Singapore Med J. 2006;47(6):518-24.

4. O'Brien KL, Dowell SF, Schwartz B, Marcy SM, Phillips WR, Gerber MA. Cough illness/bronchitis - principles of judicious use of antimicrobial agents. Pediatrics. 1998;101:178-81.

5. Rosenstein N, Phillips WR, Gerber MA, Marcy SM, Schwartz B, Dowell SF. The common cold - principles of judicious use of antimicrobial agents. Pediatrics. 1998;101:181-4.

6. Avorn J, Solomon DH. Cultural and economic factors that (mis)shape antibiotic use: the nonpharmacologic basis of therapeutics. Ann Intern Med. 2000;133(2):128-35.

7. Rousounidis A, Papaevangelou V, Hadjipanayis A, Panagakou S, Theodoridou M, Syrogiannopoulos G, Hadjichristodoulou C. Descriptive study on parents' knowledge, attitudes and practices on antibiotic use and misuse in children with upper respiratory tract infections in Cyprus. Int J Environ Res Public Health. 2011;8(8):3246-62.

8. van den Broek D'Obrenan J, Verheij TJ, Numans ME, van der Velden AW. Antibiotic use in Dutch primary care: relation between diagnosis, consultation and treatment. J Antimicrob Chemother. 2014;69(6):1701-7.

9. Panagakou SG, Spyridis N, Papaevangelou V, et al. Antibiotic use for upper respiratory tract infections in children: a cross-sectional survey of knowledge, attitudes, and practices (KAP) of parents in Greece. BMC Pediatr. 2011;11:60.

10. Friedman BC, Schwabe-Warf D, Goldman R. Reducing inappropriate antibiotic use among children with influenza infection. Can Fam Physician. 2011;57(1):42-4

11. Smith SM, Schroederk, Fahey T. Over-the-counter (OTC)medications for acute cough in children and adults in community settings. Cochrane Database of Systematic Reviews 2014, Issue 11. Art. No.: CD001831. doi: 10. 1002/14651858.CD001831.pub5

12. De Blasio F, Lanata L, Dicpingaitis PV, Saibene F, Balsamo R, Zanasi A. Efficacy of levodropropizine in the pediatric setting: a meta-analysis of published studies. Trends in Medicine. 2013;13(1):9-14.

13. De Blasio F, Dicpinigaitis PV, Rubin BK, De Danieli G, Lanata L, Zanasi A. An observational study on cough in children: epidemiology, impact on quality of sleep and treatment outcome. Cough. 2012;8(1):1.

14. Butler CC, Hood K, Verheij T, Little P, Mel bye H, Nuttall J, Kelly MJ, Mölstad S, Godycki-Cwirko M, Almirall J, Torres A, Gillespie D, Rautakorpi U, Coenen S, Goossens $\mathrm{H}$. Variation in antibiotic prescribing and its impact on recovery in patients with acute cough in primary care: prospective study in 13 countries. BMJ. 2009;338:b2242.

15. Shields MD, Bush A, Everard ML, McKenzie S, Primhak R. Recommendations for the assessment and management of cough in children. Thorax. 2008;63: iii1-iii15.

16. Zanasi A, Cazzato S, Aprile A, Mazzolini M, Zenezini C, Pandolfi P: Are antibiotics effective in treating children with acute moist cough? A retrospective study vs symptomatic therapy. Multidisciplinary Respiratory Medicine 2012;7(3-4):I-V.

17. Centre for Clinical Practice at NICE (UK). Respiratory Tract Infections Antibiotic Prescribing: Prescribing of Antibiotics for Self-Limiting Respiratory Tract Infections in Adults and Children in Primary Care. London: National Institute for Health and Clinical Excellence (UK) http://www.ncbi.nlm.nih. gov/books/NBK53632/

18. De Blasio F, Virchow JC, Polverino M, Zanasi A, Behrakis PK, Kilinç G, Balsamo R, De Danieli G, Lanata L. Cough management: a practical approach. Cough. 2011;7(1):7.

19. De Blasio F, Dicpinigaitis PV, De Danieli G, Lanata L, Zanasi A. Efficacy of levodropropizine in pediatric cough. Pulm Pharmacol Ther. 2012;25(5):337-42.

20. Dicpinigaitis PV, Morice AH, Birring SS, McGarvey L, Smith JA, Canning BJ, Page CP. Antitussive drugs - past, present, and future. Pharmacol Rev. 2014; 66(2):468-512. 